\title{
Ecuaciones de Sintonía para Controladores PID usando la Minimización del Error y de la Varianza de la Señal del Controlador como la Función Objetivo
}

\author{
Ivan D. Portnoy ${ }^{1}$, Arnaldo Verdeza', ${ }^{1,2}$, Yuhan A. Lenis ${ }^{1,3}$ y Marco E. Sanjuán'. \\ (1) Facultad de Ingeniería, Dpto. de Ingeniería Mecánica, Universidad del Norte, Barranquilla-Colombia. \\ (e-mail: iportnoy@uninorte.edu.co) \\ (2) Facultad de Ingeniería, Dpto. de Ingeniería Industrial, Universidad Simón Bolívar, Barranquilla-Colombia. \\ (e-mail: averdeza@unisimonbolivar.edu.co) \\ (3) Facultad de Ingeniería, Dpto. de Mecánica, Institución Universitaria Pascual Bravo, Medellín-Colombia \\ (e-mail: yuhan.lenis@pascualbravo.edu.co)
}

Recibido May. 10, 2018; Aceptado Jul. 12, 2018; Versión final Ago. 25, 2018, Publicado Feb. 2019

\begin{abstract}
Resumen
A partir de un modelo paramétrico para procesos de primer orden más tiempo muerto, se desarrollan ecuaciones de sintonía para controladores PID. Se usa como criterio de optimización la minimización de una función objetivo, compuesta por una combinación de la integral del valor absoluto del error (IAE) y la varianza de la señal del controlador. Se obtienen dos conjuntos de ecuaciones de sintonía, uno para $0.1<t_{0} / \tau<1.5$ y otro para $1.5<t_{0} / \tau<5.0$. Ambos conjuntos de ecuaciones de sintonía se evalúan con procesos de referencia, y sus resultados se comparan con las sintonías de mínimo IAE, integral cuadrada del error (ISE), integral cuadrada del error por el tiempo (ISTE), por control de modelo interno (IMC) y Lambda $(\lambda)$. A diferencia de las ecuaciones tradicionales, las propuestas en este trabajo consideran la respuesta de la variable controlada y la variabilidad en la señal que se envía a los actuadores.
\end{abstract}

Palaras clave: PID; sintonía; varianza; IAE; procesos de primer orden; FOPDT

\section{Tuning Equations for PID Controllers using Minimization of Error and of Controller Signal Variance as the Objective Function}

\begin{abstract}
New tuning equations for PID controllers based on first-order-plus-dead-time process parameters are developed in this work. The optimization criterion is the minimization of a target function composed by a combination of integral-of-the-absolute-error (IAE) and the controller signal variance, which considers not only the controlled variable response but also the actuators safety. Two sets of tuning equations are obtained, one for $0.1<\mathrm{t} 0 / \tau<1.5$ and another one for $1.5<\mathrm{t} / \tau<5.0$. Both tuning equation sets are assessed with benchmark processes and their performances are compared with the tuning formulas for Minimum IAE, integral of the squared error (ISTE), internal model control (IMC) and $\lambda$ tuning. Unlike traditional tuning equations, those proposed in this work consider not only the controlled variable response, but also favors responses with low variability of signals to the actuators.
\end{abstract}

Keywords: PID; tuning equations; signal variance; IAE; first order processes; FOPDT 


\section{INTRODUCCIÓN}

En 1940 se introdujo el primer controlador PID al mercado, el Fulscope modelo 100. La sintonización de dichos controladores se realizaba a prueba y error, porque no existía un método sistemático para sintonizarlos. Fueron John Ziegler y Nathaniel Nichols, ingenieros de Taylor, en 1942 los primeros en abordar el problema de sintonización (Alfaro 2005; Smith y Corripio 2005). Considerando que una buena respuesta para el lazo de control debe reportar un sobrepaso menor al $25 \%$ en la amplitud de la oscilación cuando se produce una alteración o cambio en la referencia de la variable controlada o "setpoint" (Alfaro 2005; Valério y Da Costa 2006), con este criterio se desarrollaron dos grupos de ecuaciones de sintonía, uno basado en la ganancia del controlador y el período de oscilación, y otro basado en una caracterización del proceso paso a paso, para aproximarlo a un sistema FOPDT. La dinámica de muchos procesos reales puede ajustarse bien a una función de transferencia FOPDT, por eso la sintonización Ziegler-Nichols, también conocida como sintonía QDR, ha sido ampliamente utilizada. Debido a la falta de singularidad de la sintonía QDR, Paul W. Murril y Cecil L. Smith desarrollaron ecuaciones de sintonía particulares a cada proceso, utilizando los parámetros de un proceso de FOPDT y minimizando el IAE como su función objetivo (Padma et al. 2004; Ramasamy y Sundaramoorthy 2008). Otro conjunto de ecuaciones de sintonía ampliamente utilizado fue desarrollado por Dahlin, que favorece las respuestas amortiguadas (con sobrepaso del 5\%) o sobre amortiguadas, denominadas sintonías $\lambda$ y $\lambda^{\prime}$ respectivamente, usando control de modelo interno (IMC) (Campi et al. 2002). En esta línea se destaca el trabajo de Lee et al. (2014).

De manera más general en los trabajos de O'Dwyer (2000), se brinda una completa revisión de las distintas ecuaciones de sintonía desarrolladas para los controladores Pi (O'Dwyer 2000a) y PID (O'Dwyer 2000b) y Tan at al. (2006), quienes evalúan la robustez de algunas de las ecuaciones de sintonía más usadas en la industria. Además se han desarrollado nuevos enfoques para la sintonía de controladores PID, como el uso de algoritmos genéticos para la obtención de los parámetros de sintonía (Shen 2002), o como Özdemir et al. (2015), quienes proponen el uso algoritmos metahurísticos, mezclando la optimización de enjambre y forraje bacteriano, usando como indicadores de rendimiento el IAE, la integral del cuadrado del error (ISE), integral del valor absoluto del error por el tiempo (ITAE) e integral del cuadrado del error por el tiempo (ITSE). Otro ejemplo es el trabajo de Chaib et al. (2017), que utiliza un atgoritmo de muercielago, inspirado en la ecolocalización, obtimizando IAE, ISE, ITAE e ITSE. Sin embargo, el diseño de ecuaciones de sintonía, dada su versatilidad y generalización, representan una opción para incluir la optimización de parametros específicos, ya que a través de este método, se pueden desarrollar ecuaciones orientadas a optimizar la respuesta del controlador acorde a las necesidades del proceso. Tal es el caso del trabajo de Klán y Gorez (2008) para controladores PI, que se enfoca en minimizar las variaciones en la señal de salida del controlador, con miras a la preservación de los actuadores mediante acciones de control suaves. Otro ejemplo es el realizado por Verdeza et al. (2016), quienes presentan un conjunto de ecuaciones de sintonía con aplicabilidad al control PID de fotobiorreactores, optimizando IAE y la varianza tanto de la señal de salida del controlador, como la de la variable controlada y el trabajo de Duarte y Amador (2013), quienes se enfocan en ecuaciones de sintonía para PID implementados en intercambiadores de calor.

En este trabajo se muestra el desarrollo de nuevas ecuaciones de sintonía para controladores PID basados en la caracterización de un proceso FOPDT. A diferencia de las ecuaciones de sintonía tradicionales, las propuestas en este trabajo consideran, como función objetivo a minimizar, la suma ponderada del IAE y la varianza de la señal del controlador, con el objetivo de propiciar una respuesta rápida del controlador, minimizar las desviaciones de la variable controlada y la variabilidad de la señal de salida del controlador. En consecuencia, las ecuaciones propuestas consideran no sólo la respuesta de la variable controlada, sino que también favorecen respuestas con baja variabilidad en las señales que se envían a los actuadores, buscando mantenerlos en condiciones de operación seguras y evitar el estrés por oscilaciones.

\section{METODOLOGÍA}

Con el fin de obtener las ecuaciones de sintonía para controladores PID, basadas en parámetros de un proceso FOPDT y la minimización de una función objetivo que involucra el IAE y la varianza de la señal de salida del controlador, se proponen dos diseños experimentales (con réplica) para evaluar un amplio rango de la relación to/ $\tau$, donde to es el tiempo muerto y $\tau$ la constante de tiempo. Para ambos experimentos se consideran cuatro factores; los tres parámetros del proceso FOPDT: ganancia $\mathrm{K}_{\mathrm{p}}$, constante de tiempo $\tau$, la relación $t_{0} / \tau$, y un cuarto parámetro $\Gamma$, que se utiliza como factor de peso para la varianza de la señal del controlador. En la figura 1 se muestra el esquema de control implementado para obtener los parámetros de sintonía del controlador PID (ganancia $K_{c}$, tiempo integral $T_{i}$ y derivativo $T_{d}$ ), hasta encontrar los valores óptimos, para cada condición experimental $K_{p}, \tau$, to y $\Gamma$. Para ello se usa la función fmincon de MatLab® la cual permite encontrar el mínimo de una función no lineal de varias variables, incorporando como valores iniciales los parámetros $K_{c}, T_{i}$ y $T_{d}$, obtenidos a través de la sintonía IAE y $\lambda$ ' (respectivamente en cada réplica experimental) y definiendo los límites de la simulación para cada uno de dichos parámetros, de forma que excedan los valores extremos considerados por las técnicas tradicionales de sintonía IAE y $\lambda^{\prime}$ (Ramasamy y 
Sundaramoorthy 2008; Campi et al. 2002; Verdeza et al. 2016). La función objetivo a minimizar es definida en la ecuación 1.

$$
V P=\int|e(t)| d t+\Gamma \sigma^{2}(m(t))
$$

Todas las simulaciones se evalúan para una misma cantidad de unidades de tiempo (100 unidades de tiempo en total, 50 unidades para cambios de referencia en la variable controlada y 50 para perturbaciones) y un paso a paso fijo de 0.001 unidades de tiempo. La elección del tiempo de simulación se basa en el hecho de que es lo suficientemente amplio como para que el proceso (en lazo cerrado) alcance el estado estable en la región de muestreo evaluada experimentalmente. EI IAE y la varianza de $\mathrm{m}(\mathrm{t})$, para cada condición experimental, se calculan utilizando las señales (del sensor y el actuador) acumuladas durante la simulación. Para ambos diseños de experimentos se seleccionó una región de muestreo representativa de los procesos más usados en la industria, con una relación de to/ $\tau$ entre 0.10 y 5.00 (Smith y Corripio 2005; O’Dwyer 2009). Una vez ejecutada la función de optimización (minimizando VP, ecuación 1), los parámetros de sintonía obtenidos para cada prueba son los resultados de los diseños de experimentos.

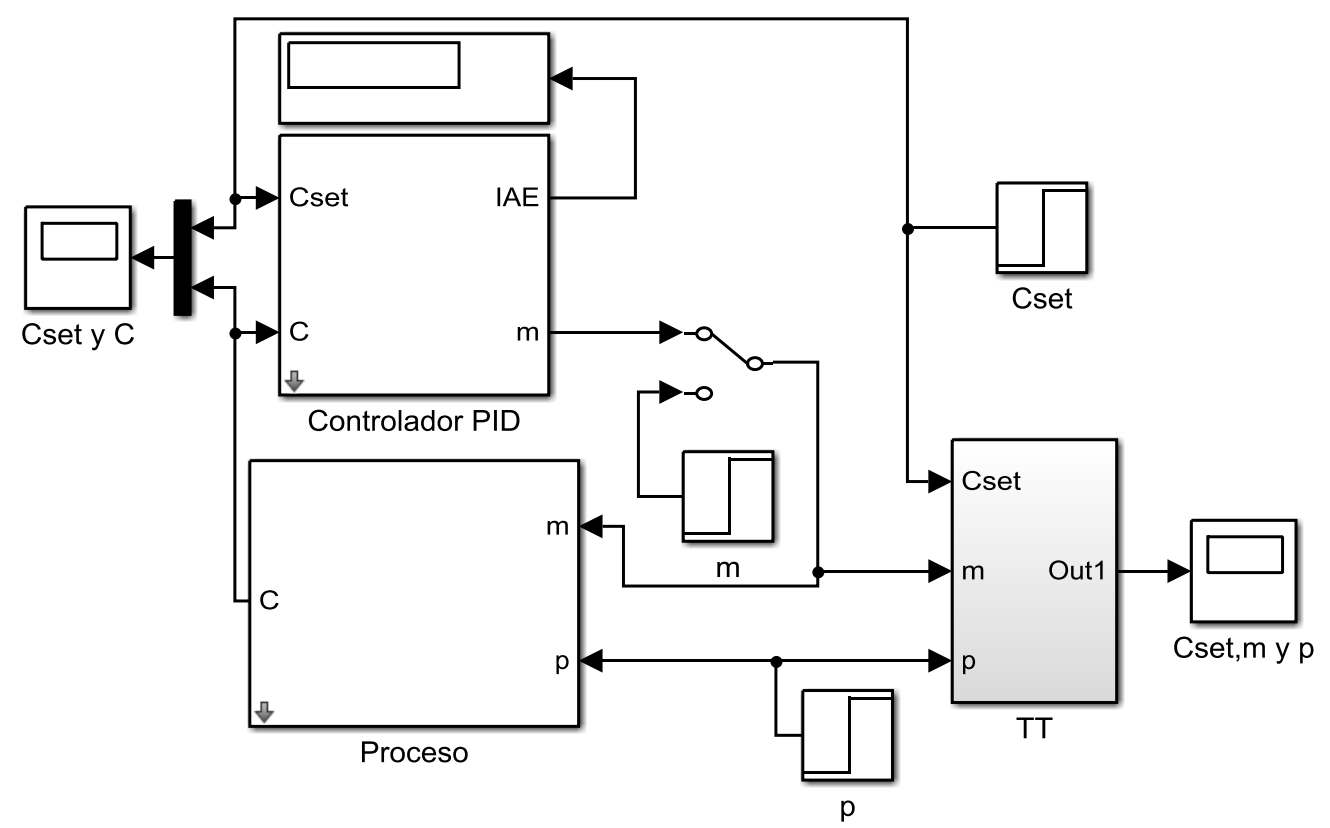

Fig. 1: Esquema de control simulado

El análisis de los resultados experimentales sólo considera los efectos de primer orden y se utilizó el software Statgraphics Centurion XVIB para el tratamiento de los datos. Las ecuaciones de sintonía obtenidas se comparan con las ecuaciones de sintonía mínimo IAE, como una referencia de control agresiva, y las ecuaciones de sintonía $\lambda^{\prime}$ como una referencia de control lenta o pasiva (Poe y Mokhatab 2017; Smith y Corripio 2005). Además, se comparan con las ecuaciones de sintonía mínimo ISE, ISTE (Tan et al. 2006), y por control de modelo interno (IMC) propuestas por Lee at al. (2014), que consideran la varianza de la señal de salida del controlador como punto de optimización. En las tablas 1 y 2 se muestran las ecuaciones implementadas con sus respectivos coeficientes.

Tabla 1: Ecuaciones de sintonía para perturbaciones mínimo IAE, ISE e ISTE.

\begin{tabular}{|c|c|c|c|c|c|c|}
\hline \multirow{2}{*}{ Ecuaciones de sintonía } & \multicolumn{2}{|c|}{$\begin{array}{c}\text { Coeficientes mínimo IAE } \\
\text { (Smith y Corripio 2005) }\end{array}$} & \multicolumn{2}{c|}{$\begin{array}{c}\text { Coeficientes mínimo ISE } \\
\text { (Tan et al. 2006) }\end{array}$} & \multicolumn{2}{c|}{$\begin{array}{c}\text { Coeficientes mínimo ISTE } \\
\text { (Tan et al. 2006) }\end{array}$} \\
\cline { 2 - 7 } & $a_{1}$ & $a_{2}$ & $a_{1}$ & $a_{2}$ & $a_{1}$ & $a_{2}$ \\
\hline $\mathrm{K}_{\mathrm{c}}=\frac{\mathrm{a}_{1}}{\mathrm{~K}_{\mathrm{p}}}\left(\frac{\mathrm{t}_{0}}{\tau}\right)^{\mathrm{a}_{2}}$ & 1.435 & -0.921 & 1.474 & -0.970 & 1.468 & -0.970 \\
\hline $\mathrm{T}_{\mathrm{i}}=\frac{\tau}{\mathrm{a}_{1}}\left(\frac{\mathrm{t}_{\mathrm{o}}}{\tau}\right)^{\mathrm{a}_{2}}$ & 0.878 & 0.749 & 1.115 & -0.753 & 0.942 & -0.725 \\
\hline $\mathrm{T}_{\mathrm{d}}=\mathrm{a}_{1} \tau\left(\frac{\mathrm{t}_{0}}{\tau}\right)^{\mathrm{a}_{2}}$ & 0.482 & 1.137 & 0.550 & 0.948 & 0.443 & 0.939 \\
\hline
\end{tabular}


Tabla 2: Ecuaciones de sintonía para cambio de referencia mínimo IAE, ISE, ISTE, IMC y $\lambda$ '.

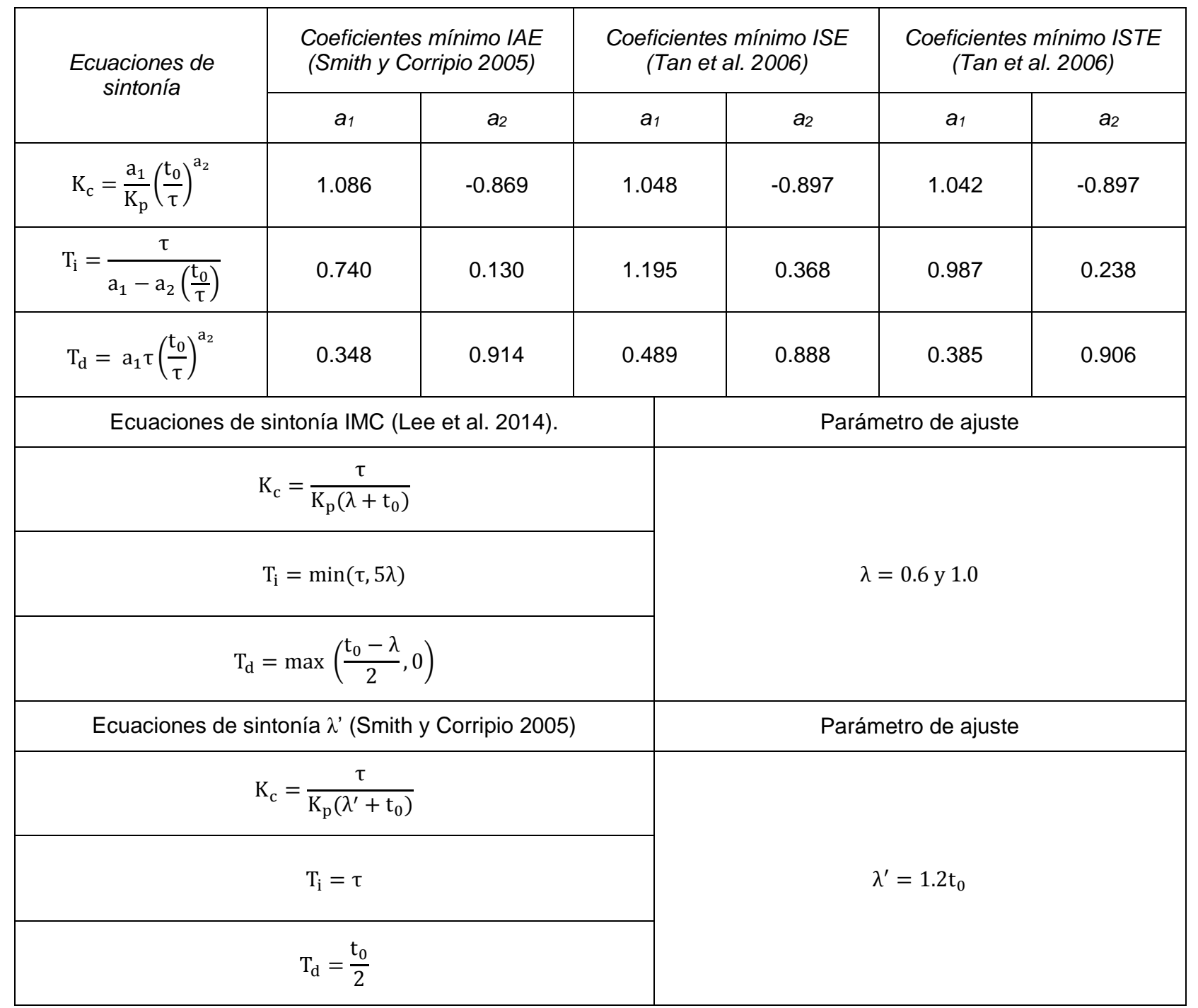

Usualmente la variación en la señal de salida del controlador es grande durante la parte inicial del transitorio y luego, se acerca a la referencia y en ocasiones la sobrepasa, mostrando un comportamiento oscilatorio. De hecho, incluso después de mucho tiempo, la variable controlada no es absolutamente constante, dado que el control por retroalimentación responde cambios continuos en el proceso, debido a las perturbaciones y ruido de medición. En consecuencia, existen diversas formas de caracterizar la actividad del sistema de control después de una perturbación o cambio en la referencia de la variable controlada (Klan y Gorez 2008; Smith y Corripio 2005). En nuestro caso se evalúa el rendimiento del controlador de forma cuantitativa, mediante el IAE y la varianza de la señal de salida del controlador.

\section{RESULTADOS}

Como se menciona en la sección anterior, se desarrollan dos diseños experimentales con replica, usando deferentes semillas (sintonías mínimo IAE y $\lambda^{\prime}$ ), considerando cuatro factores; la ganancia $K_{p}$, constante de tiempo $\tau$, la relación $t_{0} / \tau$, y el factor de peso $\Gamma$. Una vez realizado el análisis de varianza (ANOVA), no se encontró diferencia significativa entre ambas réplicas de los diseños de experimentos. A continuación se presenta el análisis de los diseños de experimentos realizados y las ecuaciones obtenidas.

\section{Primer diseño experimental}

El primer diseño experimental, considera un multifactorial $5^{4}$. Los niveles definidos para cada factor se muestran en la tabla 3. Se encontró que para la ganancia del controlador $\mathrm{K}_{\mathrm{c}}$, resultaron significativos los factores $K_{p}, \Gamma$ y to $/ \tau$. Para el tiempo integral $T_{i}$, resultaron significativos $K_{p}, \Gamma, \tau$ y to $/ \tau$. Y para el tiempo derivativo $T_{d}$, resultaron significativos $\tau$ y to $/ \tau$. Con los datos experimentales se obtuvieron modelos de regresión para cada parámetro del controlador PID, como se muestra en la tabla 4 con su respectivo ajuste $\mathrm{R}^{2}$. Este grupo de ecuaciones sólo es funcional para el intervalo entre $0.1<t_{0} / \tau<1.5$. 
Tabla 3: Factores y niveles del primer diseño experimental.

\begin{tabular}{|c|c|c|c|c|}
\hline Nivel & $K_{p}$ & $\tau$ & $t o / \tau$ & $\Gamma$ \\
\hline Bajo & 0.500 & 0.500 & 0.100 & 1.000 \\
\hline Medio-Bajo & 1.250 & 1.125 & 0.450 & 25.750 \\
\hline Medio & 2.000 & 1.750 & 0.80 & 50.500 \\
\hline Medio-Alto & 2.750 & 2.375 & 1.150 & 75.250 \\
\hline Alto & 3.500 & 3.000 & 1.500 & 100.000 \\
\hline
\end{tabular}

Tabla 4: Ecuaciones de regresión obtenidas a partir del primer diseño de experimentos para controladores PID.

\begin{tabular}{|c|c|c|c|c|c|}
\hline \multirow{2}{*}{ Ecuación } & \multicolumn{4}{|c|}{ Coeficientes } & $R^{2}$ \\
\cline { 2 - 6 } & $a_{1}$ & $a_{2}$ & $a_{3}$ & 0.898 \\
\hline $\mathrm{K}_{\mathrm{c}}=\frac{\mathrm{a}_{1}}{\mathrm{~K}_{\mathrm{p}}} \Gamma^{\mathrm{a}_{2}}\left(\frac{\mathrm{t}_{0}}{\tau}\right)^{\mathrm{a}_{3}}$ & 0.9952 & -0.0848 & -0.1956 & 0.2285 & 0.985 \\
\hline $\mathrm{T}_{\mathrm{i}}=\mathrm{a}_{1} \tau^{\mathrm{a}_{2}} \Gamma^{\mathrm{a}_{3}}\left(\frac{\mathrm{t}}{\tau}\right)^{\mathrm{a}_{4}}$ & 1.5806 & 0.9980 & -0.0180 & - & 0.971 \\
\hline $\mathrm{T}_{\mathrm{d}}=\mathrm{a}_{1} \tau^{\mathrm{a}_{2}}\left(\frac{\mathrm{t}_{0}}{\tau}\right)^{\mathrm{a}_{3}}$ & 0.2743 & 0.9965 & 1.0861 & - & 0.97 \\
\hline
\end{tabular}

\section{Segundo diseño experimental}

El segundo diseño experimentos fue un multifactorial $3^{4}$ como se muestra en la tabla 5. Para la ganancia del controlador $\mathrm{K}_{c}$, resultaron significativos los factores $\mathrm{K}_{\mathrm{p}}$ y la relación to/ $\tau$. Para el tiempo integral $\mathrm{T}_{\mathrm{i}}$, resultaron significativos $\mathrm{K}_{\mathrm{p}}$, la constante de tiempo $\tau$ y la relación to $/ \tau$. $\mathrm{Y}$ para el tiempo derivativo $\mathrm{T}_{\mathrm{d}}$, resultaron significativos la constante de tiempo $\tau, \Gamma$ y la relación $t_{0} / \tau$. Con los datos experimentales se obtuvieron modelos de regresión para cada parámetro del controlador PID, mostrados en la tabla 6 con su respectivo ajuste $\mathrm{R}^{2}$. Este grupo de ecuaciones sólo es funcional para el intervalo entre $1.5<t_{0} / \tau<5.0$.

Tabla 5: Factores y niveles del segundo diseño experimental.

\begin{tabular}{|c|c|c|c|c|}
\hline Nivel & $K_{p}$ & $\tau$ & to/ & $\Gamma$ \\
\hline Bajo & 0.500 & 0.500 & 1.500 & 100.000 \\
\hline Medio & 2.000 & 3.000 & 3.250 & 50005000.000 \\
\hline Alto & 3.500 & 5.500 & 5.000 & $1.000 \times 10^{8}$ \\
\hline
\end{tabular}

Tabla 6: Primer conjunto de ecuaciones de regresión a partir del segundo diseño experimental.

\begin{tabular}{|c|c|c|c|c|c|}
\hline \multirow{2}{*}{ Ecuación } & \multicolumn{5}{|c|}{ Coeficientes } \\
\hline & $a_{1}$ & $a_{2}$ & $a_{3}$ & $a_{4}$ & $R^{2}$ \\
\hline $\mathrm{K}_{\mathrm{c}}=\frac{\mathrm{a}_{1}}{\mathrm{~K}_{\mathrm{p}}}\left(\frac{\mathrm{t}_{0}}{\tau}\right)^{\mathrm{a}_{2}}$ & 0.7211 & -0.1845 & - & - & 0.999 \\
\hline $\mathrm{T}_{\mathrm{i}}=\mathrm{a}_{1} \tau^{\mathrm{a}_{2}}\left(\frac{\mathrm{t}_{0}}{\tau}\right)^{\mathrm{a}_{3}}$ & 1.7577 & 0.8643 & 0.5021 & - & 0.978 \\
\hline $\mathrm{T}_{\mathrm{d} 1}=\mathrm{a}_{1} \tau^{\mathrm{a}_{2}} \Gamma^{\mathrm{a}_{3}}\left(\frac{\mathrm{t}_{0}}{\tau}\right)^{\mathrm{a}_{4}}$ & 0.3997 & 0.9518 & 0.0095 & 0.6409 & 0.980 \\
\hline $\mathrm{T}_{\mathrm{d} 2}=\mathrm{a}_{1} \tau^{\mathrm{a}_{2}}\left(\frac{\mathrm{t}_{0}}{\tau}\right)^{\mathrm{a}_{3}}$ & 0.3144 & 1.0305 & 0.6708 & - & 0.973 \\
\hline
\end{tabular}

Como es de notarse, la correlación para $T_{d}$ se calculó dos veces; primero incluyendo el factor $\Gamma$ y luego sin él. Ya que $\Gamma$ fue el factor que resultó con el menor índice de significancia para $T_{d}$, y luego de obtener la correlación excluyendo $\Gamma$, esta muestra un buen ajuste del estadístico $\mathrm{R}^{2}$. Por tanto si sólo se considera la ecuación $\mathrm{T}_{\mathrm{d} 2}$, 
se puede usar $\Gamma=100$ y la función objetivo queda definida como se muestra en la ecuación 2.

$$
V P=\int l e(t) \mid d t+100 \sigma^{2}(m(t))
$$

Finalmente, las ecuaciones de sintonía obtenidas para cada parámetro del controlador PID se muestran en la tabla 7 con su respectivo ajuste $\mathrm{R}^{2}$, este conjunto de ecuaciones sólo es funcional para el intervalo entre $1.5<\mathrm{t}_{0} / \tau<5.0$.

Tabla 7: Ecuaciones obtenidas a partir del segundo diseño de experimentos para controladores PID.

\begin{tabular}{|c|c|c|c|c|}
\hline \multirow{2}{*}{ Ecuación } & \multicolumn{4}{|c|}{ Coeficientes } \\
\hline & $a_{1}$ & $a_{2}$ & $a_{3}$ & $R^{2}$ \\
\hline $\mathrm{K}_{\mathrm{c}}=\frac{\mathrm{a}_{1}}{\mathrm{~K}_{\mathrm{p}}}\left(\frac{\mathrm{t}_{0}}{\tau}\right)^{\mathrm{a}_{2}}$ & 0.7211 & -0.1845 & - & 0.999 \\
\hline $\mathrm{T}_{\mathrm{i}}=\mathrm{a}_{1} \tau^{\mathrm{a}_{2}}\left(\frac{\mathrm{t}_{0}}{\tau}\right)^{\mathrm{a}_{3}}$ & 1.7577 & 0.8643 & 0.5021 & 0.978 \\
\hline $\mathrm{T}_{\mathrm{d}}=\mathrm{a}_{1} \tau^{\mathrm{a}_{2}}\left(\frac{\mathrm{t}_{0}}{\tau}\right)^{\mathrm{a}_{3}}$ & 0.3144 & 1.0305 & 0.6708 & 0.973 \\
\hline
\end{tabular}

La evaluación de las ecuaciones obtenidas se realiza bajo dos escenarios o casos de estudio, puesto que se desarrollan dos grupos de ecuaciones de sintonía, uno para el intervalo $0.1<t 0 / \tau<1.5$ y otro para $1.5<t 0 / \tau<5.0$. El desempeño de las ecuaciones se compara con las sintonías mínimo IAE, ISE e ISTE, tanto para cambios de referencia como para perturbaciones, además se compara con las sintonías IMC; $\lambda$ ' y la propuesta por Lee at al.(2014) Los criterios de desempeño que se usan son el IAE y la varianza de la señal del controlador.

\section{Primer escenario de evaluación}

El proceso usado para la evaluar el desempeño del primer conjunto de ecuaciones de sintonía es un reactor refrigerado, como se muestra en la figura 2.

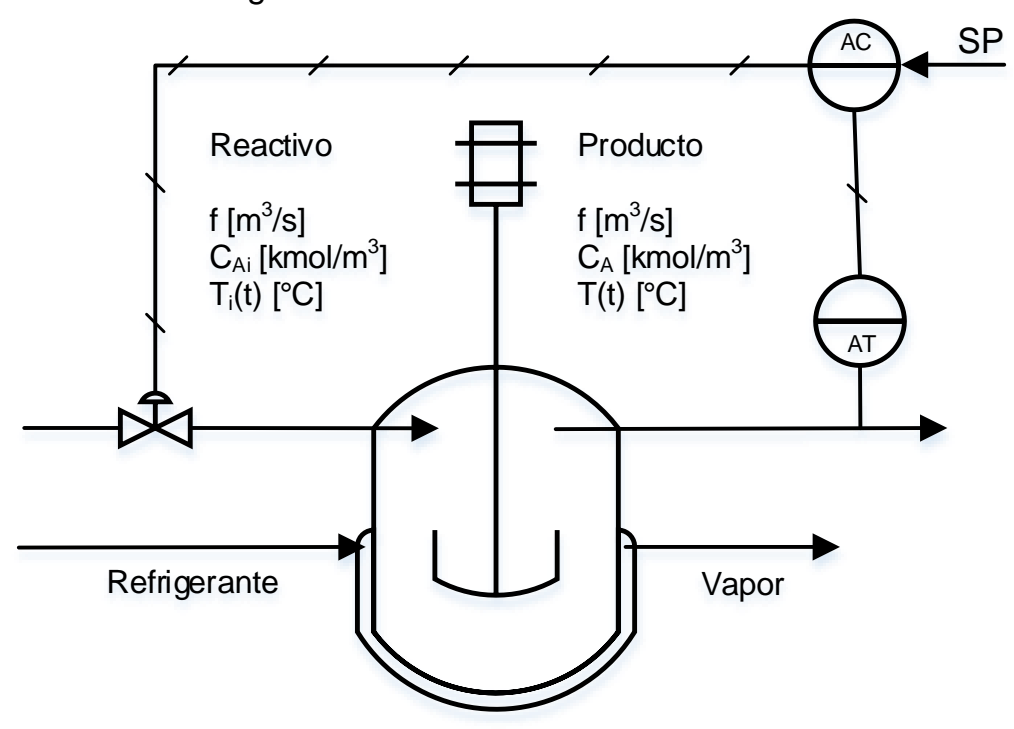

Fig. 2: Esquemático reactor refrigerado

El reactor está aislado térmicamente y en su interior tiene lugar una reacción exotérmica $A \rightarrow B$, se asume una agitación constante y homogénea, la capacidad calorífica $C_{p}$ y la densidad de reactivos y productos son iguales. La tabla 8, muestra un resumen de la información del proceso y los valores en estado estable. La modelación se realiza a través de un balance molar del reactivo $A$, un balance de energía para el reactor y la ecuación de velocidad de reacción, resumidas en las ecuaciones 3, 4 y 5 respectivamente.

$f c_{A i}(t)-f c_{A}(t)-V r_{A}(t)=V \frac{d c_{A}(t)}{d t}$ 


$$
\begin{aligned}
& f \rho C_{p} T_{i}(t)-U A\left(T(t)-T_{c}\right)-f \rho C_{p} T(t)-V r_{A}(t)\left(\Delta H_{r}\right)=V \rho C_{v} \frac{d T(t)}{d t} \\
& r_{A}(t)=k_{0} e^{-\frac{E}{R T(t)}} c_{A}(t)
\end{aligned}
$$

\begin{tabular}{|c|c|}
\hline Variable & Símbolo/Valor \\
\hline \multicolumn{2}{|c|}{ Información del proceso } \\
\hline \multicolumn{2}{|l|}{ Reactor } \\
\hline Volumen del reactor & $V=375.48 \mathrm{~L}$ \\
\hline Área de transferencia de calor & $A=3.344 \mathrm{~m}^{2}$ \\
\hline Energía de activación & $\mathrm{E}=64709.6 \mathrm{~kJ} / \mathrm{kmol}$ \\
\hline Constante de gases & $\mathrm{R}=8.314 \mathrm{~kJ} / \mathrm{kmol} \cdot \mathrm{K}$ \\
\hline Densidad & $\rho=881.02 \mathrm{~kg} / \mathrm{m}^{3}$ \\
\hline Calor especifico a presión constante & $\mathrm{C}_{p}=3.684 \mathrm{~kJ} / \mathrm{kg} \cdot \mathrm{K}$ \\
\hline Entalpía de reacción & $\Delta \mathrm{H}_{\mathrm{r}}=-27912 \mathrm{~kJ} / \mathrm{kg}$ \\
\hline Coeficiente de trasferencia de calor & $\mathrm{U}=425.87 \mathrm{~W} /\left(\mathrm{m}^{2} \cdot \mathrm{K}\right)$ \\
\hline Factor Pre-exponencial & $\mathrm{k}_{\mathrm{o}}=1.081 \mathrm{e} 91 /\left(\mathrm{m}^{3} \cdot \mathrm{kg} \cdot \mathrm{s}\right)$ \\
\hline \multicolumn{2}{|c|}{ Chaqueta refrigerada con agua } \\
\hline Volumen de la chaqueta & $V=44.17 \mathrm{~L}$ \\
\hline Calor especifico a presión constante agua & $\mathrm{C}_{p}=4.186 \mathrm{~kJ} / \mathrm{kg} \cdot \mathrm{K}$ \\
\hline Densidad agua & $\rho=999.55 \mathrm{~kg} / \mathrm{m}^{3}$ \\
\hline \multicolumn{2}{|c|}{ Valores en estado estable } \\
\hline \multicolumn{2}{|l|}{ Reactor } \\
\hline Concentración de A, entrada & $C_{A i}(t)=9570.76 \mathrm{kmol} / \mathrm{m}^{3}$ \\
\hline Temperatura de entrada & $\mathrm{T}_{\mathrm{i}}=79.63^{\circ} \mathrm{C}$ \\
\hline Flujo & $f_{i}=0.4139 \mathrm{~L} / \mathrm{s}$ \\
\hline Concentración de A, salida & $\mathrm{C}_{\mathrm{A}}(\mathrm{t})=3315.73 \mathrm{kmol} / \mathrm{m}^{3}$ \\
\hline Temperatura de salida $A$ & $\mathrm{~T}=104.02^{\circ} \mathrm{C}$ \\
\hline \multicolumn{2}{|c|}{ Chaqueta refrigerada con agua } \\
\hline Temperatura del refrigerante, entrada & $\mathrm{T}_{\mathrm{c}}=26.85^{\circ} \mathrm{C}$ \\
\hline Flujo del refrigerante & $f_{c}=0.6307 \mathrm{~L} / \mathrm{s}$ \\
\hline Temperatura del refrigerante, salida & $\mathrm{T}_{\mathrm{co}}=61.68^{\circ} \mathrm{C}$ \\
\hline
\end{tabular}

Tabla 8: Información del proceso y valores en estado estable.

Desempeño ante cambios de referencia: Una vez modelado el proceso y obtenidos los valores de sintonía, utilizando $\Gamma=50$ y $\Gamma=100$, se realiza una prueba variando la referencia de la variable controlada. En este caso se varía la concentración desde 3315.73 hasta $3647.30 \mathrm{kmol} / \mathrm{m}^{3}$. El rendimiento de las ecuaciones de sintonía se muestra en la tabla 9, donde cada conjunto de ecuaciones es evaluado cuantitativamente mediante el IAE y la varianza de la señal del controlador, además, en la figura 3 se muestra la respuesta de la variable controlada y la señal del controlador en la figura 4 para las ecuaciones con mejor rendimiento cuantitativo. El valor de IAE obtenido con las ecuaciones de sintonía propuestas, usando $\Gamma=50$, fue mayor que los obtenidos por mínimo IAE, ISE e ISTE. Por otro lado, para $\Gamma=100$ el valor de IAE fue mayor que aquel obtenido por mínimo IAE, ISE, ISTE y $\lambda$ '. Sin embargo, este resultado no es una sorpresa, ya que, como se mencionó anteriormente, las ecuaciones de sintonía propuestas apuntan no solo a minimizar el IAE, sino también a proteger la integridad de los actuadores, al evitar condiciones de operación oscilatoria. Nótese que los valores de la varianza de la señal del controlador obtenidos con la sintonía a través de las ecuaciones propuestas (para $\Gamma=50$ y $\Gamma=100$ ) son los menores, y solo las ecuaciones de sintonización $\lambda$ ' mostraron un resultado 
cercano. Por otro lado, con las ecuaciones de sintonía propuestas, la variable controlada se aproxima más rápido a la referencia que usando las ecuaciones de sintonía $\lambda$ '.

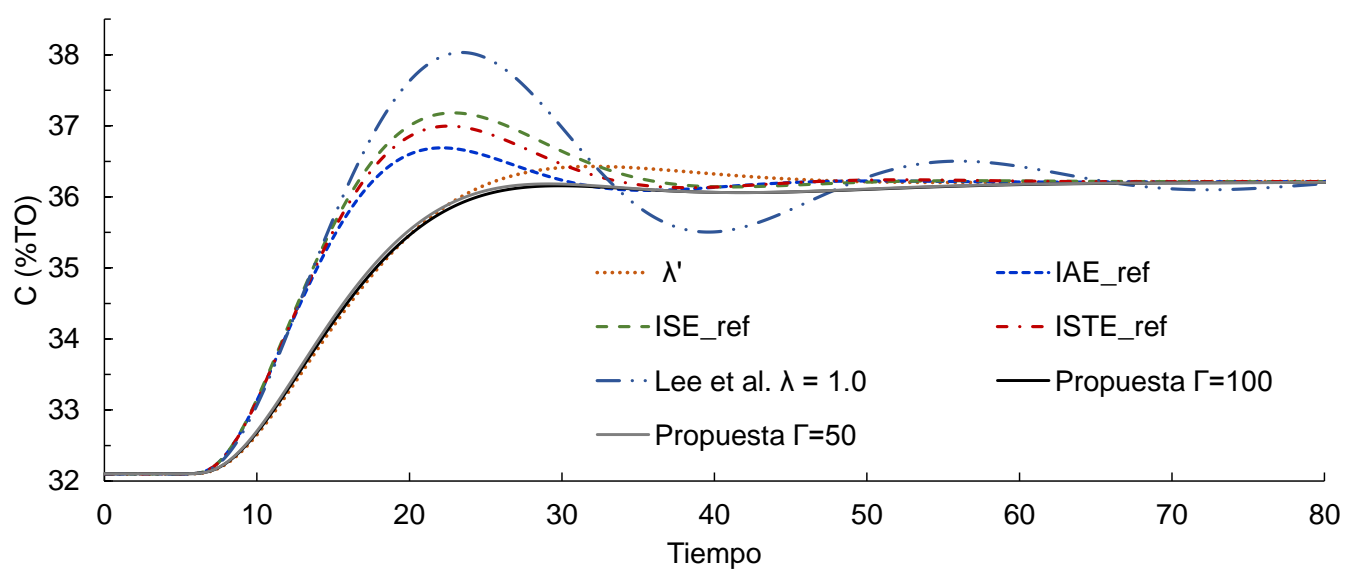

Fig. 3: Respuesta de la variable controlada ante un cambio de referencia para cada conjunto de ecuaciones.

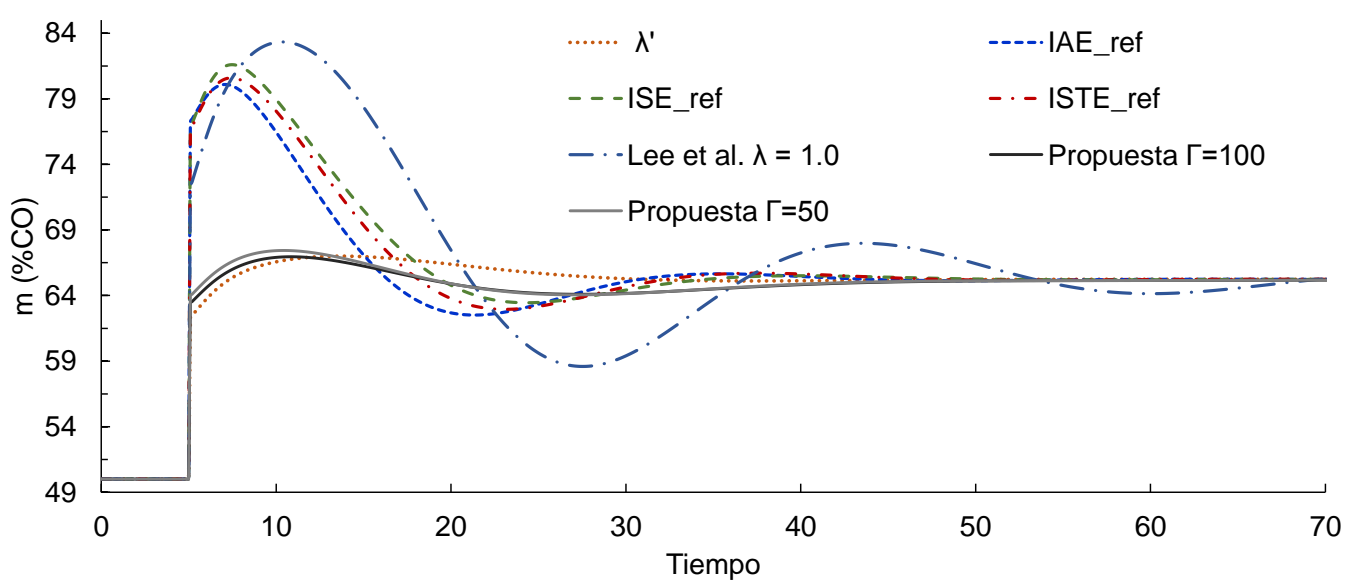

Fig. 4: Señal del controlador ante un cambio de referencia para cada conjunto de ecuaciones.

Tabla 9: Parámetros cuantitativos de desempeño Integral absoluta del error (IAE) la varianza de la señal de salida del controlador, para cambios de referencia en el escenario primer de evaluación.

\begin{tabular}{|c|c|c|c|c|c|}
\hline Ecuaciones de Sintonía & $\mathrm{K}_{\mathrm{c}}$ & $\mathrm{T}_{\mathrm{i}}$ & $\mathrm{T}_{\mathrm{d}}$ & $\mathrm{IAE}$ & $\sigma^{2}(\mathrm{~m}(\mathrm{t}))$ \\
\hline IAE & 6.570 & 11.648 & 1.609 & 34.477 & 15.877 \\
\hline ISE & 6.442 & 7.869 & 2.294 & 40.034 & 18.757 \\
\hline ISTE & 6.405 & 9.206 & 1.788 & 37.597 & 17.390 \\
\hline Lee at al. $\lambda=0.6$ & 5.735 & 3.000 & 1.901 & 164.830 & 149.403 \\
\hline Lee at al. $\lambda=1.0$ & 5.310 & 5.000 & 1.701 & 60.199 & 28.916 \\
\hline$\lambda^{\prime}$ & 2.962 & 7.760 & 2.201 & 45.334 & 7.832 \\
\hline Propuesta $\Gamma=100$ & 3.228 & 9.878 & 1.142 & 46.600 & 7.638 \\
\hline Propuesta $\Gamma=50$ & 3.363 & 10.002 & 1.142 & 45.292 & 7.757 \\
\hline
\end{tabular}

Desempeño ante perturbaciones: La evaluación para las ecuaciones ante una perturbación, se realiza introduciendo un paso escalón en la concentración de reactivo, entre 9570.76 y $10527.83 \mathrm{kmol} / \mathrm{m}^{3}$. Las respuestas obtenidas para la variable controlada ante los diferentes conjuntos de ecuaciones de sintonía se muestran en la figura 5, y en la figura 6 se muestran las señales del controlador. Los valores de IAE y varianza de la señal del controlador, se muestran en la tabla 10. Nótese que para las ecuaciones de sintonía propuestas, usando $\Gamma=50$ y $\Gamma=100$, se obtuvieron valores para el IAE cercanos a los obtenidos para la sintonía realizada con las ecuaciones $\lambda^{\prime}$, por encima de todas las ecuaciones de sintonía restantes, además, obtuvieron los menores valores para la varianza en la señal del controlador. 


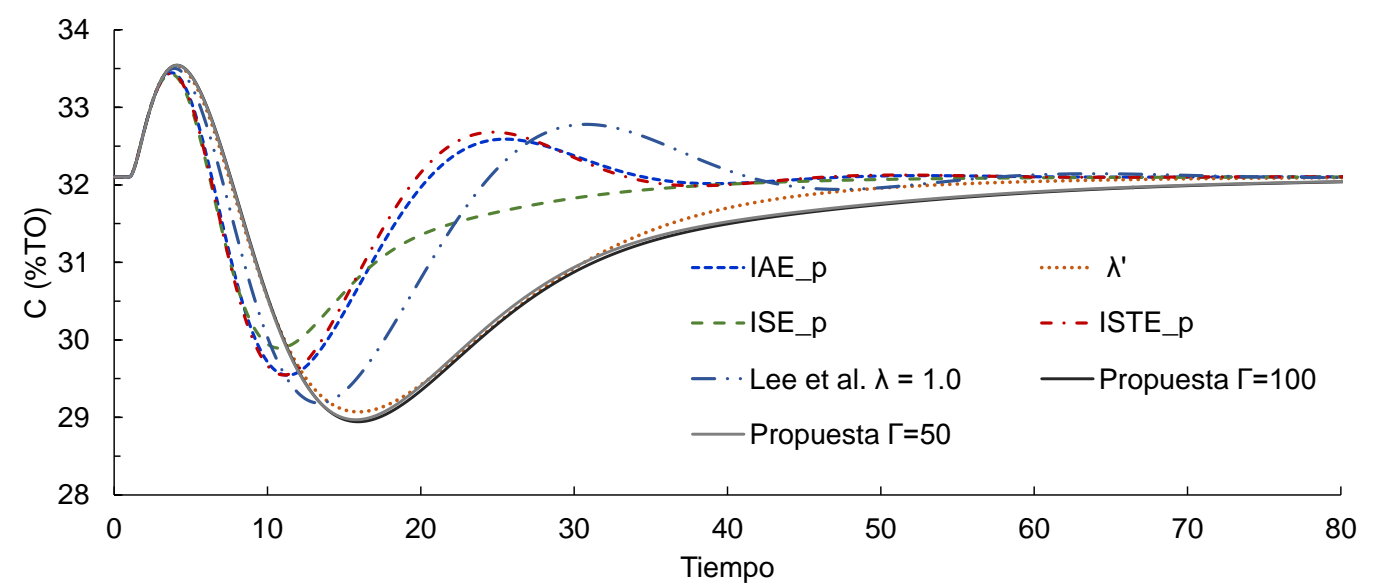

Fig. 5: Respuesta de la variable controlada ante una perturbación para cada conjunto de ecuaciones.

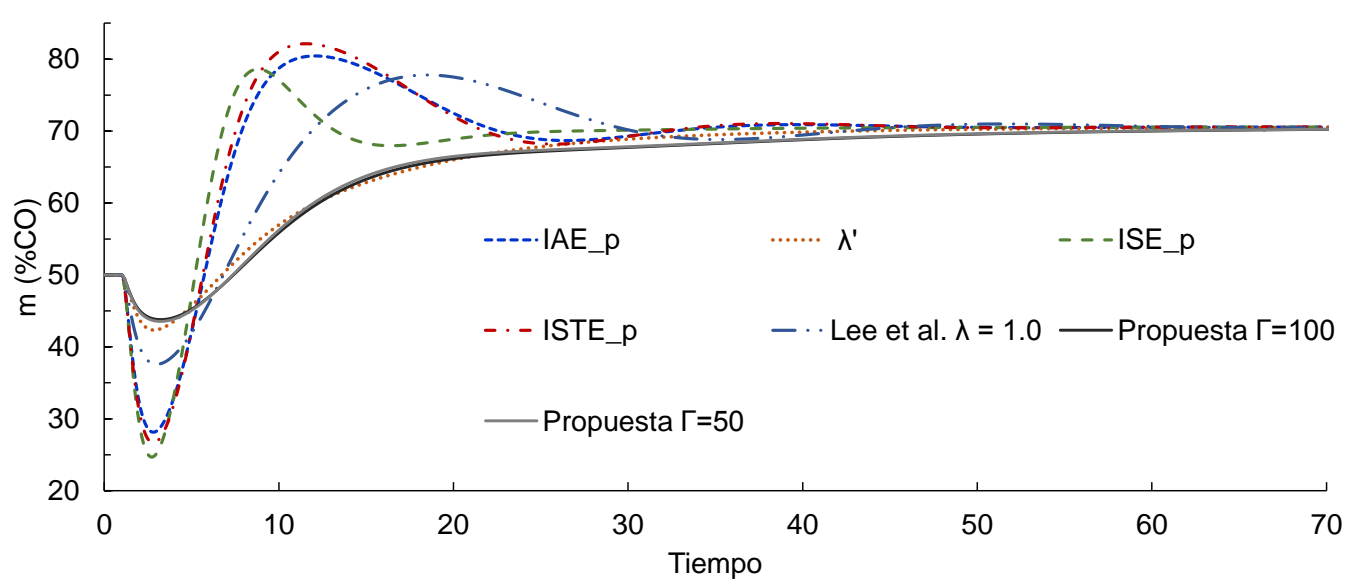

Fig. 6: Señal del controlador ante una perturbación para cada conjunto de ecuaciones.

Tabla 10: Parámetros cuantitativos de desempeño Integral absoluta del error (IAE) la varianza de la señal de salida del controlador, para perturbaciones en el primer escenario de evaluación.

\begin{tabular}{|c|c|c|c|c|c|}
\hline Ecuaciones de Sintonía & $K_{c}$ & $T_{i}$ & $T_{d}$ & $I A E$ & $\sigma^{2}(m(t))$ \\
\hline IAE & 8.941 & 5.781 & 1.963 & 30.457 & 46.917 \\
\hline ISE & 9.436 & 10.666 & 2.494 & 31.713 & 42.712 \\
\hline ISTE & 9.404 & 5.462 & 2.019 & 30.407 & 50.012 \\
\hline Lee at al. $\lambda=0.6$ & 5.735 & 3.000 & 1.901 & 74.587 & 73.353 \\
\hline Lee at al. $\lambda=1.0$ & 5.310 & 5.000 & 1.701 & 44.384 & 40.776 \\
\hline$\lambda^{\prime}$ & 2.962 & 7.760 & 2.201 & 65.329 & 33.703 \\
\hline Propuesta $\Gamma=100$ & 3.228 & 9.878 & 1.142 & 74.651 & 33.612 \\
\hline Propuesta $\Gamma=50$ & 3.363 & 10.002 & 1.142 & 72.823 & 33.478 \\
\hline
\end{tabular}

\section{Segundo escenario de evaluación}

El proceso usado para evaluar el segundo conjunto de ecuaciones de sintonía es un tanque de mezclado de agua fría y caliente, como se ilustra en la figura 7. La variable controlada es la temperatura de salida, mientras que la variable manipulada es el flujo de agua fría que ingresa al tanque. Se considera un proceso no lineal y con un retraso por fenómenos de trasferencia de calor (que se asocia a un tiempo muerto), tal que la relación $1.5<\mathrm{t} / \mathrm{\tau}<5.0$ se cumpla. La temperatura de salida en estado estable es $\mathrm{T}_{4}=73.0^{\circ} \mathrm{C}$, el resto de la información del proceso y los valores para el estado estable se muestran en la tabla 11. Las ecuaciones que rigen el comportamiento dinámico del proceso, se componen de un balance de masa, un balance de energía y un retraso por transporte, como se resume en las ecuaciones $6,7,8$ y 9 respectivamente.

$\mathrm{w}_{1}(\mathrm{t})+\mathrm{w}_{2}(\mathrm{t})-\mathrm{w}(\mathrm{t})=0$ 
$w_{1}(t) C_{p} T_{1}(t)+w_{2}(t) C_{p} T_{2}(t)-w C_{p} T_{3}(t)=\rho V C_{v} \frac{d T_{3}(t)}{d t}$

$\mathrm{T}_{4}(\mathrm{t})=\mathrm{T}_{3}\left(\mathrm{t}-\mathrm{t}_{0}(t)\right)$

$t_{0}(t)=\frac{L A \rho}{w(t)}$

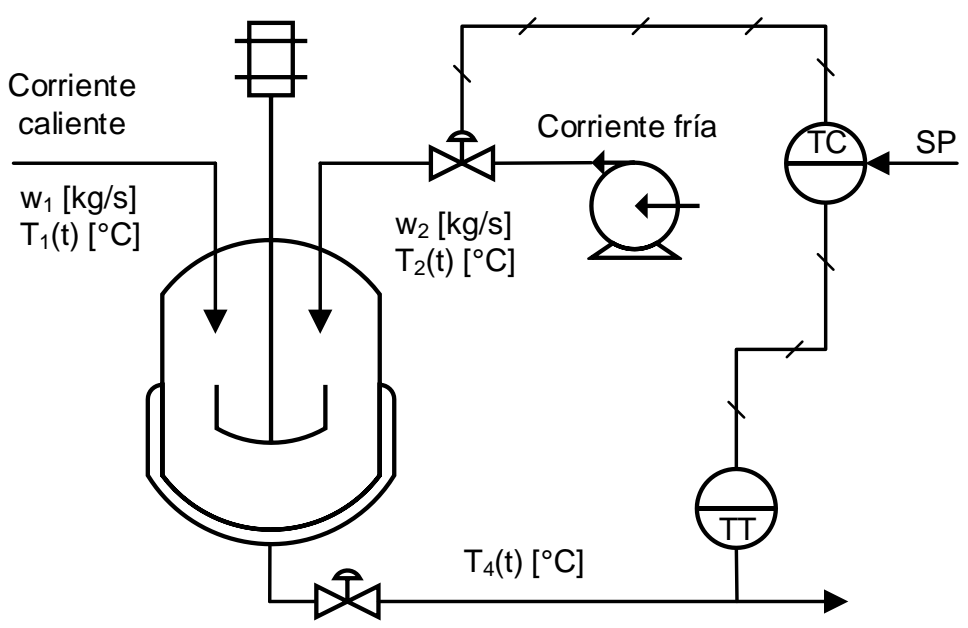

Fig. 7: Esquemático tanque de mezclado.

Tabla 11: Información del proceso y valores en estado estable.

\begin{tabular}{|c|c|}
\hline \multicolumn{2}{|c|}{ Información del proceso } \\
\hline \multicolumn{2}{|l|}{ Tanque } \\
\hline Variable & Símbolo/Valor \\
\hline Volumen & $V=28.32 \mathrm{~L}$ \\
\hline \multicolumn{2}{|c|}{ Tubería de salida } \\
\hline Longitud & $\mathrm{L}=37.80 \mathrm{~m}$ \\
\hline Área trasversal & $A_{c}=1.858 e-2 m^{2}$ \\
\hline \multicolumn{2}{|l|}{ Válvula (FC-P) } \\
\hline Flujo máximo & $\mathrm{f}_{\max }=188.78 \mathrm{~L} / \mathrm{s}$ \\
\hline Constante de tiempo & $\tau_{\mathrm{v}}=24 \mathrm{~s}$ \\
\hline \multicolumn{2}{|c|}{ Sensor/Transmisor } \\
\hline Cero del instrumento & $\mathrm{PV}_{\min }=37.78^{\circ} \mathrm{C}$ \\
\hline Span & $\mathrm{sp}=37.78^{\circ} \mathrm{C}$ \\
\hline Constante de tiempo & $\tau_{\mathrm{T}}=30 \mathrm{~s}$ \\
\hline \multicolumn{2}{|l|}{ Flujo de agua } \\
\hline Calor específico a presión constante & $\mathrm{C}_{p}=3.349 \mathrm{~kJ} / \mathrm{kg} \cdot \mathrm{K}$ \\
\hline Calor específico a volumen constante & $\mathrm{C}_{\mathrm{v}}=3.768 \mathrm{~kJ} / \mathrm{kg} \cdot \mathrm{K}$ \\
\hline Densidad & $\rho=961.12 \mathrm{~kg} / \mathrm{m}^{3}$ \\
\hline \multicolumn{2}{|c|}{ Valores en estado estable } \\
\hline Flujo de calor corriente caliente & $w_{1}=1.890 \mathrm{~kg} / \mathrm{s}$ \\
\hline Flujo de calor corriente fría & $\mathrm{W}_{2}=1.4452 \mathrm{~kg} / \mathrm{s}$ \\
\hline Temperatura corriente caliente & $\mathrm{T}_{1}=121.11^{\circ} \mathrm{C}$ \\
\hline Temperatura corriente fría & $\mathrm{T}_{2}=10^{\circ} \mathrm{C}$ \\
\hline
\end{tabular}


Desempeño ante cambios de referencia: Al igual que para el primer conjunto de ecuaciones de sintonía propuestas, para el segundo grupo, se realiza una prueba variando la referencia de 73.0 a $71.2{ }^{\circ} \mathrm{C}$ y se obtienen los valores de sintonía para IAE, ISE, ISTE, $\lambda^{\prime}$ y Lee at al. (2014). El rendimiento de las ecuaciones de sintonía se muestra en la tabla 12, donde cada grupo de ecuaciones es evaluado cuantitativamente mediante el IAE y la varianza de la señal del controlador. Además, las figuras 8 y 9 muestran la respuesta de la variable controlada y señal del controlador para cada conjunto de ecuaciones de sintonía. Nótese que las ecuaciones propuestas obtuvieron el mejor desempeño para IAE. La varianza de la señal del controlador estuvo por debajo de las sintonías $\lambda^{\prime}$ y las propuestas por Lee at al. (2014).

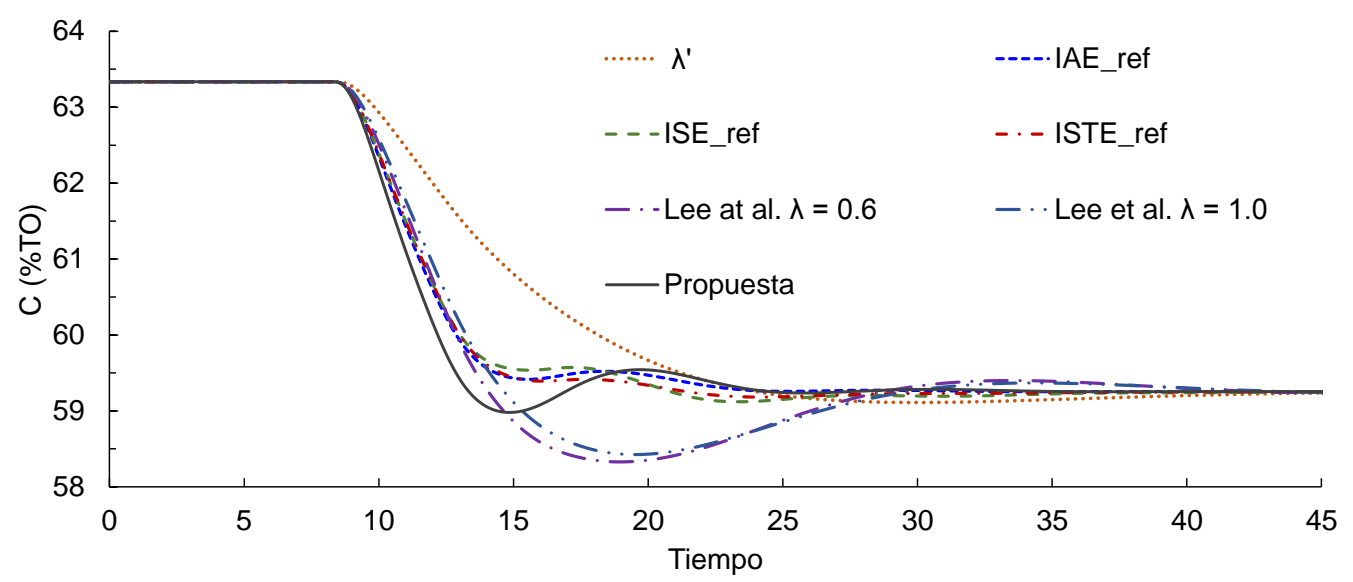

Fig. 8: Respuesta de la variable controlada ante un cambio de referencia para cada conjunto de ecuaciones.

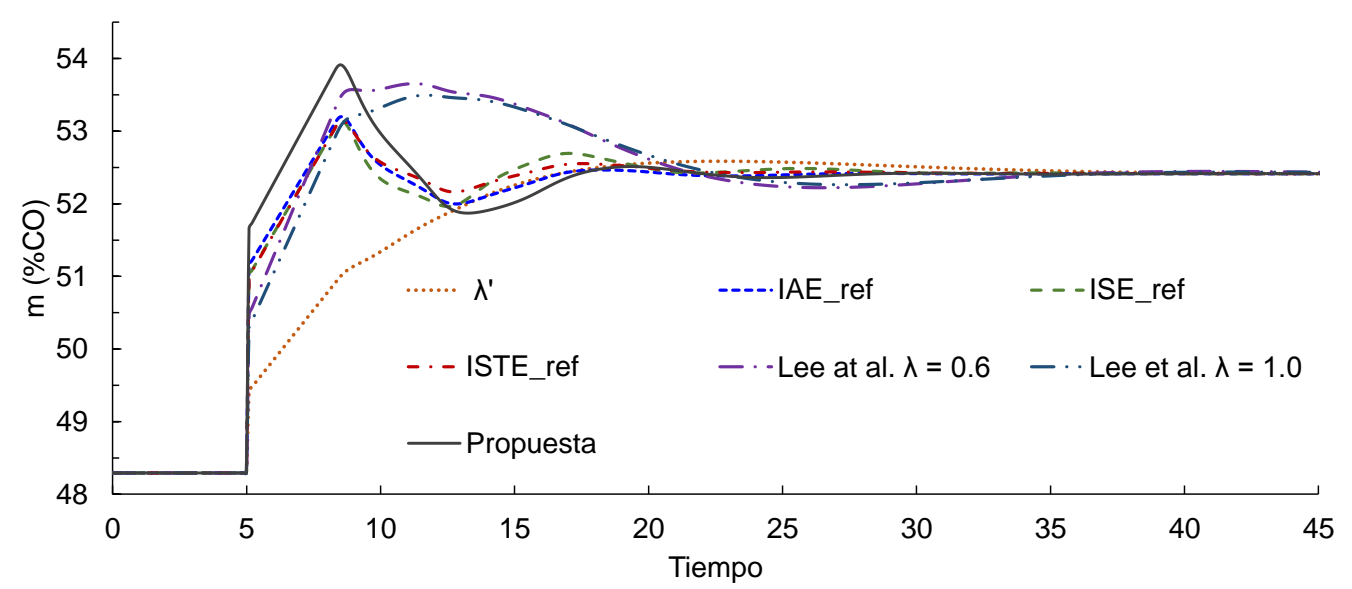

Fig. 9: Señal del controlador ante un cambio de referencia para cada conjunto de ecuaciones.

Tabla 12: Parámetros cuantitativos de desempeño Integral absoluta del error (IAE) la varianza de la señal de salida del controlador, para cambios de referencia en el segundo escenario de evaluación.

\begin{tabular}{|c|c|c|c|c|c|}
\hline Ecuaciones de Sintonía & $\mathrm{K}_{\mathrm{c}}$ & $\mathrm{T}_{\mathrm{i}}$ & $\mathrm{T}_{\mathrm{d}}$ & $\mathrm{IAE}$ & $\sigma^{2}(\mathrm{~m}(\mathrm{t}))$ \\
\hline IAE & 0,687 & 4,592 & 1,356 & 27.546 & 0.6937 \\
\hline ISE & 0,653 & 4,224 & 1,878 & 28.773 & 0.6999 \\
\hline ISTE & 0,649 & 4,172 & 1,494 & 27.560 & 0.6976 \\
\hline Lee at al. $\lambda=0.6$ & 0,514 & 2,369 & 1,741 & 35.740 & 0.8151 \\
\hline Lee at al. $\lambda=1.0$ & 0,473 & 2,369 & 1,541 & 35.435 & 0.7990 \\
\hline$\lambda^{\prime}$ & 0,268 & 2,369 & 2,041 & 40.106 & 0.8290 \\
\hline Propuesta & 0.809 & 4.869 & 1.102 & 26.117 & 0.7225 \\
\hline
\end{tabular}

Desempeño ante perturbaciones: La evaluación para las ecuaciones ante una perturbación se realiza introduciendo un paso escalón en el flujo de agua caliente de 1.890 a $1.985 \mathrm{~kg} / \mathrm{s}$. Las respuestas obtenidas para los diferentes grupos de ecuaciones de sintonía y sus respectivos valores de IAE y varianza de la señal del controlador se muestran en la tabla 13 y en las figuras 10 y 11 . Con las ecuaciones de sintonía propuestas se obtuvo una respuesta más rápida que las obtenidas con las demás ecuaciones de sintonía, alcanzando 
rápidamente la referencia y logrando estabilizarse con pocas oscilaciones. La varianza de la señal del controlador calculada para las ecuaciones propuestas resultó ser el menor valor obtenido, así como también el IAE, comparado con el resto de las ecuaciones de sintonías probadas, exhibiendo una respuesta con pequeñas oscilaciones, haciendo notable que al usar las ecuaciones propuestas se logra un mejor rendimiento tanto para el IAE como para la varianza calculada de la señal del controlador cuando se cumple que $1.5<\mathrm{t}_{0} / \tau<5.0$.

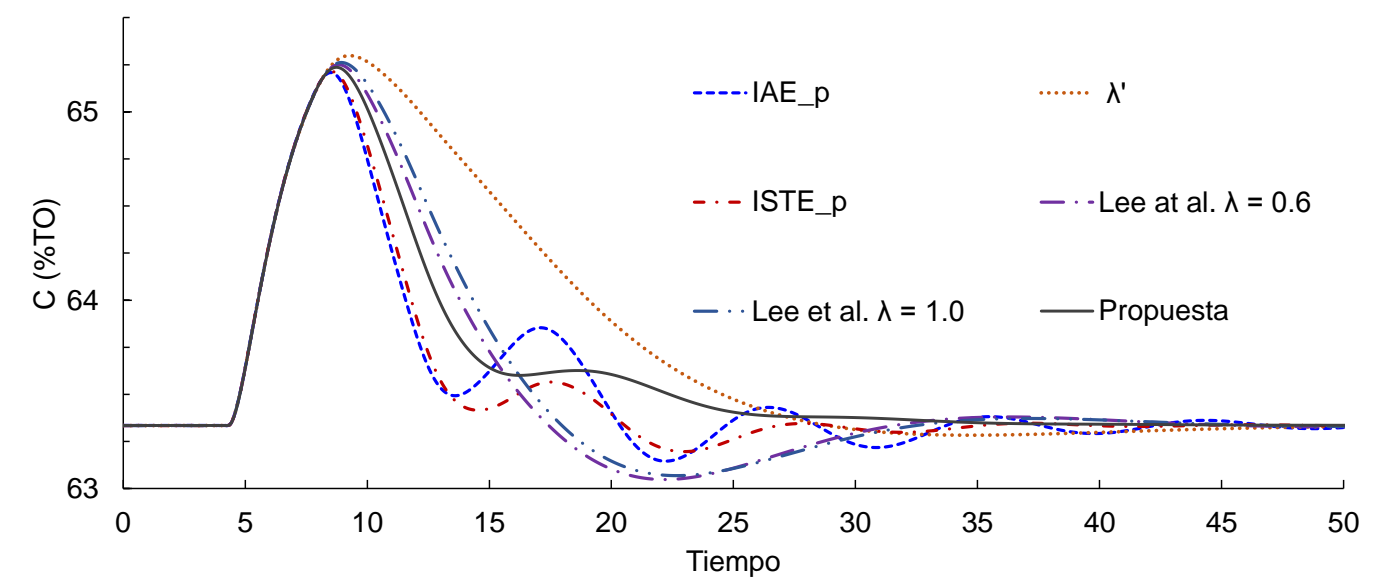

Fig. 10: Respuesta de la variable controlada ante una perturbación para cada conjunto de ecuaciones.

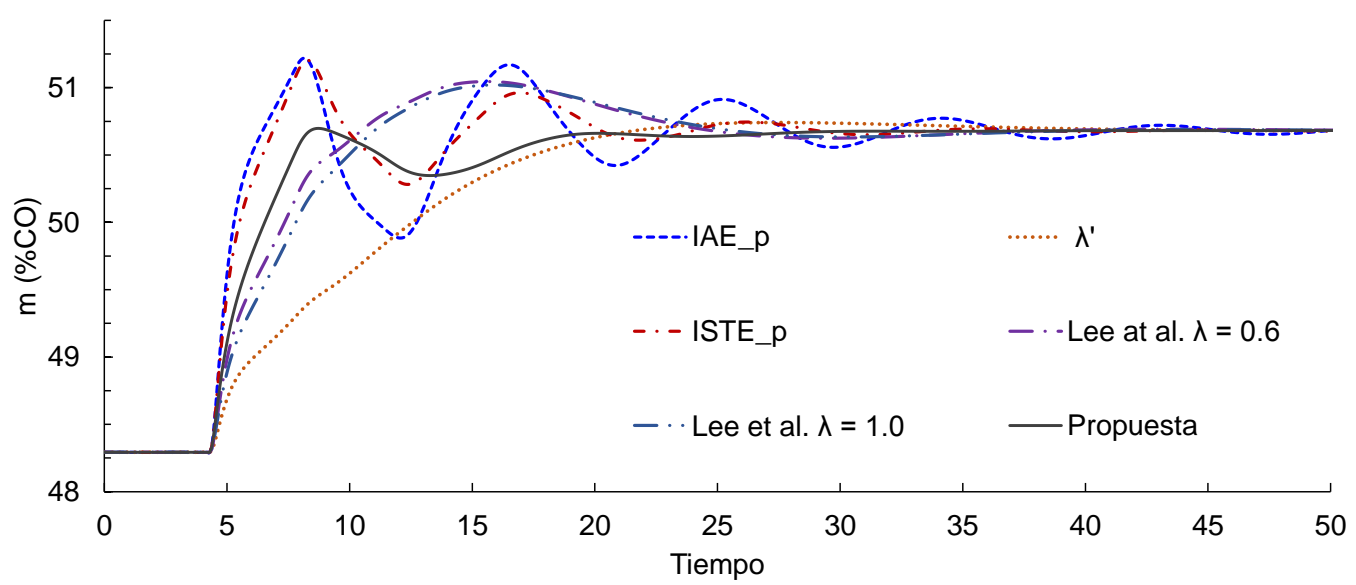

Fig. 11: Señal del controlador ante una perturbación para cada conjunto de ecuaciones.

Tabla 13: Parámetros cuantitativos de desempeño Integral absoluta del error (IAE) la varianza de la señal de salida del controlador, para perturbaciones en el segundo escenario de evaluación.

\begin{tabular}{|c|c|c|c|c|c|}
\hline Ecuaciones de Sintonía & $K_{c}$ & $T_{i}$ & $T_{d}$ & $I A E$ & $\sigma^{2}(m(t))$ \\
\hline IAE & 0.883 & 4.056 & 2.120 & 28.951 & 0.8261 \\
\hline ISE & 0.882 & 1.411 & 2.183 & 164.653 & 6.3972 \\
\hline ISTE & 0.879 & 3.732 & 1.750 & 28.427 & 0.8292 \\
\hline Lee at al. $\lambda=0.6$ & 0,514 & 2,369 & 1,741 & 35.740 & 0.8151 \\
\hline Lee at al. $\lambda=1.0$ & 0,473 & 2,369 & 1,541 & 35.435 & 0.7990 \\
\hline$\lambda^{\prime}$ & 0,268 & 2,369 & 2,041 & 40.106 & 0.8290 \\
\hline Propuesta & 0.809 & 4.869 & 1.102 & 26.117 & 0.7225 \\
\hline
\end{tabular}

\section{CONCLUSIONES}

Se desarrollaron dos grupos de ecuaciones de sintonía para controladores PID basados en la caracterización de procesos FOPDT para $0.1<\mathrm{t}_{0} / \tau<1.5$ y $1.5<\mathrm{t}_{0} / \tau<5.0$. A diferencia de las ecuaciones de sintonía tradicionales, las propuestas en este trabajo consideran no solo la respuesta de la variable controlada, sino que además favorecen respuestas con baja variabilidad de las señales que se envían a los actuadores, buscando condiciones de operación seguras. Las ecuaciones desarrolladas en este trabajo se compararon con seis 
conjuntos de ecuaciones de sintonía tomadas de la bibliografía reciente, implementándolas en dos procesos de referencia y evaluando su desempeño con respecto al mínimo IAE y la varianza de la señal de salida del controlador. Dichas ecuaciones mostraron un buen rendimiento en procesos con $1.5<t_{0} / \tau<5.0$, superando las ecuaciones de sintonía con las que se comparó, obteniéndose una respuesta rápida con suaves y bajas oscilaciones. Sin embargo, para procesos con $0.1<t_{0} / \tau<1.5$, el ajuste propuesto mostró un comportamiento comparable con el ajuste Lambda, es decir, una respuesta no oscilatoria y lenta.

\section{AGRADECIMIENTOS}

Los autores agradecen el apoyo de COLCIENCIAS a través de la Convocatoria Doctorados Nacionales 727/757, del Fondo nacional de financiamiento para la ciencia, la tecnología e innovación FCTel del sistema general de regalías SGR, Universidad del Norte y Universidad Simón Bolívar Barranquilla-Colombia.

\section{REFERENCIAS}

Alfaro, V.M., Actualización del Método de Sintonización de Controladores de Ziegler y Nichols, Revista Ingeniería de la Universidad de Costa Rica, ISSN: 2215-2652, 15(1-2), 39-52 (2005)

Campi, M.C., A. Lecchini y S.M. Savaresi, Virtual Reference Feedback Tuning: A Direct Method for the Design of Feedback Controllers, doi: 10.1016/S0005-1098(02)00032-8, Automática, 38(8), 1337-1346 (2002)

Chaib, L., A. Choucha y S. Arif, Optimal Design and Tuning of Novel Fractional Order PID Power System Stabilizer Using a New Metaheuristic Bat Algorithm, doi: 10.1016/j.asej.2015.08.003, Ain Shams Engineering Journal, 8(2), 113-125 (2017)

Duarte, J. y G. Amador, Desarrollo de Ecuaciones de Sintonía para Controladores Tipo PID Aplicados al Control de Temperatura en Intercambiadores de Calor, Inge@UAN, ISSN: 2346-1446, 4(7), 21-28 (2013)

Klan, P. y R. Gorez, PI Controller Design for Actuator Preservation, doi: 10.3182/20080706-5-KR-1001.00981, IFAC Proceedings Volumes, 41(2), 5820-5824 (2008)

Lee, J., W. Cho y T.F. Edgar, Simple Analytic PID Controller Tuning Rules Revisited, doi: 10.1021/ie4009919, Industrial and Engineering Chemistry Research, 53(13), 5038-5047 (2014)

O'Dwyer, A., Handbook of PI and PID Controller Tuning Ruler, $3^{\text {th }}$ Ed., Imperial College Press, London, UK (2009)

O'Dwyer, A., A Summary of PI and PID Controller Tuning Rules for Processes with Time Delay. Part 1: PI Controller Tuning Rules, doi: 10.1016/S1474-6670(17)38237-X," IFAC Proceedings Volumes, 33(4), 175-180 (2000a)

O'Dwyer, A., A Summary of PI and PID Controller Tuning Rules for Processes with Time Delay. Part 2: PID Controller Tuning Rules, doi: 10.1016/S1474-6670(17)38246-0, IFAC Proceedings Volumes, 33(4), 175-180 (2000b)

Özdemir, M.T., D. Öztürk, I. Eke, V. Çelik y K.Y. Lee, Tuning of Optimal Classical and Fractional Order PID Parameters for Automatic Generation Control Based on the Bacterial Swarm Optimization, doi: 10.1016/j.ifacol.2015.12.429, IFACPapersOnLine, 48(30), 501-506 (2015)

Padma, R., M.N. Srinivas y M. Chidambaram, A Simple Method of Tuning PID Controllers for Stable and Unstable FOPTD Systems, doi: 10.1016/j.compchemeng.2004.04.004, Computers and Chemical Engineering, 28(11), 2201-2218 (2004)

Poe, W.A. y S. Mokhatab, Process Control, in Modeling, Control, and Optimization of Natural Gas Processing Plants $1^{\text {st }}$ Ed., 97-172, Gulf Professional Publishing, Canada, USA (2017)

Ramasamy, M. y S. Sundaramoorthy, PID Controller Tuning for Desired Closed-Loop Responses for SISO Systems Using Impulse Response, doi:10.1016/j.compchemeng.2007.08.019, Computers and Chemical Engineering, 32(8), 1773-1788 (2008)

Shen, J.C., New Tuning Method for PID Controller, doi: 10.1016/S0019-0578(07)60103-7, ISA Transactions, 41(4), 473484 (2002)

Smith, C.A. y A.B. Corripio, Adjusting Controller Parameters; in Principles and Practices of Automatic Process Control, $3^{\text {th }}$ Ed., 229-279 John Wiley \& Sons, South Florida, Tampa, USA (2005)

Tan, W., J. Liu, T. Chen y H.J. Marquez, Comparison of Some Well-Known PID Tuning Formulas, doi: 10.1016/j.compchemeng.2006.04.001, Computers and Chemical Engineering, 30(9), 1416-1423 (2006)

Valério, D. y J.S. Da Costa, Tuning of Fractional PID Controllers with Ziegler-Nichols-Type Rules, doi: 10.1016/j.sigpro.2006.02.020, Signal Processing, 86(10), 2771-2784 (2006)

Verdeza, A., L. Di-Mare, M. Sanjuán y A. Bula, Diseño de Ecuaciones de Sintonía para Controladores PID (ProporcionalIntegral-Derivativo) Implementados en Fotobiorreactores, doi: 10.4067/S0718-07642016000400013, Información Tecnológica, 27(4), 121-132 (2016) 
